\title{
Chronic subdural hematomas: a case series from the medical ward of a north Tanzanian referral hospital
}

\author{
Sakina Mehboob Rashid ${ }^{1 * \dagger}$ D , Shahrzad Seyedeh Deliran ${ }^{2 \dagger}$, Marieke Cornelia Johanna Dekker ${ }^{1,3,4,5}$ and \\ William Patrick Howlett ${ }^{3}$
}

\begin{abstract}
Background: Chronic subdural hematomas (CSDH) initially present as focal neurological deficits with or without signs of increased intracranial pressure, for which admission to the general medical ward may occur if they present with poorly understood neurological deficits and no evident history of trauma. The symptoms may be long standing and mimic stroke upon presentation. Their distribution and specific clinical features in sub-Saharan Africa are largely unknown.

Methods: We describe a series of subdural hematoma (SDH) inpatients from the medical ward of a tertiary referral center in Northern Tanzania, describing clinical and radiological characteristics and providing clinical outcome where possible.

Results: Our study population numbered 30, with a male majority $(n=19,63.3 \%)$ and a mean age of $66.8 \pm 14.5$ years. Mean duration from symptom onset to admission in the medical ward was $20.0 \pm 30.8$ days. History of head injury was reported in only $43.3 \%$ of patients. Improvement in the neurological examination was noted in $68.1 \%$ of the 22 patients who underwent surgery. The mortality rate was $20.0 \%$.

Conclusion: A majority of the patients were elderly males and presented late to the hospital. Delayed presentation and diagnosis due to, amongst other reasons, postponed imaging resulted in a prolonged time to definitive treatment and a high mortality rate compared to other regions of the world.
\end{abstract}

Keywords: Chronic subdural hematomas, Medical department, North Tanzania, Neurosurgical access

\section{Introduction}

Subdural hematoma (SDH) is a hemorrhage between the dura mater and arachnoidea meningeal layers of the skull. A gradual accumulation of blood between the dura mater and the arachnoidea occurring over a period of 2 or more weeks would appear isodense or hypodense (relative to brain matter) on computed tomography (CT) imaging of the brain. Chronic subdural hematoma (CSDH) can present with focal neurological signs such as hemiplegia, seizures, altered mental status, and signs

\footnotetext{
* Correspondence: sakina.rashid@ymail.com

'Sakina Mehboob Rashid and Shahrzad Seyedeh Deliran contributed equally to this work.

${ }^{1}$ Department of General Surgery, Kilimanjaro Christian Medical Centre, P.O.

Box 3010, Moshi, Tanzania

Full list of author information is available at the end of the article
}

of raised intracranial pressure such as headache, vomiting, and papilledema [1].

The CSDH incidence has a positive correlation with increasing age and the associated physiological brain atrophy as the bridging veins between the tabula interna of the skull and the surface of the brain are stretched and thus more prone to rupture following even a trivial head injury [2].

SDHs can be surgically treated, which has the potential for significant improvement or even resolution of symptoms within minutes to days postoperatively. Brain imaging, which is often unaffordable and scarcely available in Northern Tanzania [3], therefore has major potential treatment and long-term outcome consequences.

The incidence rates of CSDH have been well described in higher-income regions of the world, and they 
demonstrate a positive correlation with increasing age; in a Japanese cohort, an incidence rate of 58 per 100,000 per year was noted in people above the age of 70 years, and a Welsh study reported an incidence rate of 273 per 100,000 per year in the population aged 95 years and above $[4,5]$.

CSDHs contribute significantly to the neurosurgical burden of disease in sub-Saharan African countries [6-11]. Generally, a younger cohort is observed, and it is thought that this may be due to the increased incidence of trauma in the region as well as a lower life expectancy compared to the higher-income countries $[6,7,10]$. The challenges of accessibility to diagnostic imaging services, due to financial constraints or more simply availability, have also been discussed in African literature $[12,13]$. The availability of neurosurgical expertise on the continent is far below that required to meet the demand; in some African countries, successful treatment of this intracranial bleed is carried out by general surgeons [14].

We present a series of SDH patients who were admitted to the Department of Internal Medicine in an academic referral center in Northern Tanzania. This paper highlights the presentation and management of CSDHs, a condition largely managed surgically, in a subSaharan African country. It illustrates the delay in management due to postponed imaging in a low resource environment.

\section{Methods}

This was a retrospective hospital-based study. Inpatients diagnosed with a CSDH or sub-acute SDH over the period of 2007-2015 in the Medical Department at Kilimanjaro Christian Medical Centre (KCMC), a tertiary referral hospital in Northern Tanzania, were included in the sample size. The main complains were identified either by interviewing the patient or obtaining a detailed history from the informant.

Patients underwent a complete clinical neurological examination by one or more of the authors. CT scanning was performed in all patients who were included in this study. Possible causes of stroke mimics like electrolyte imbalance, intoxications, or a malignancy were ruled out by basic neurological exam, laboratory investigations, and CT scanning.

In those patients who were referred for surgery, clinical outcome was retrieved wherever possible. Missing data, such as misplaced medical records, could occasionally be proxied through general surgery or anesthesia registration sources.

Variables were analyzed descriptively after running the data base through the Statistical Package for the Social Sciences Software Version 23.

\section{Results}

A total of 30 patients with radiologically confirmed CSDH or subacute SDH (male 19, female 11) were enrolled in this study. The mean age of the patient population was 66.8 years (standard deviation \pm 14.5 ) with a recorded age range of 34 to 94 years.

The most common presenting feature was hemiparesis ( $n=19,63.3 \%)$, followed by headaches $(n=16,53.3 \%)$ and aphasia $(n=5,16.7 \%)$ (Table 1). Patients experienced the presenting complains for a mean duration of 20.1 days (standard deviation \pm 30.8) before seeking medical attention, and the range of time from symptoms onset to medical ward admission was 1 to 120 days. A history of head injury was reported in $43.3 \%$ of the patients included in the study (Table 1). A record of the Glasgow Coma Scale (GCS) was noted for only 8 (26.6\%) of the admissions before and after surgery (Table 1).

The authors acknowledge that an impaired sensorium as a presenting feature would supersede other complains. Most patients presented with multiple complaints, and each complaint was noted. Table 1 presents the proportion of patients who presented with each complaint.

Table 1 Patient's history of head trauma and clinical features

\begin{tabular}{|c|c|c|}
\hline \multicolumn{3}{|l|}{ History of head injury $(n=13)$} \\
\hline Fall injury & \multicolumn{2}{|l|}{$6 / 13$} \\
\hline Road traffic crash & \multicolumn{2}{|l|}{$5 / 13$} \\
\hline Unclear cause $^{a}$ & \multicolumn{2}{|l|}{$2 / 13$} \\
\hline \multicolumn{3}{|l|}{ Presenting complaint $n(\%)$} \\
\hline Hemiparesis & \multicolumn{2}{|l|}{$10(60.0)$} \\
\hline Headache & \multicolumn{2}{|l|}{$15(50.0)$} \\
\hline Aphasia & \multicolumn{2}{|l|}{$5(16.7)$} \\
\hline Confusion & \multicolumn{2}{|l|}{$4(13.3)$} \\
\hline Convulsions & \multicolumn{2}{|l|}{$4(13.3)$} \\
\hline Complete loss of consciousness & \multicolumn{2}{|l|}{$3(10.0)$} \\
\hline Vomiting & \multicolumn{2}{|l|}{$2(6.7)$} \\
\hline Focal seizures & \multicolumn{2}{|l|}{$2(6.7)$} \\
\hline Loss of power in lower limbs & \multicolumn{2}{|l|}{$2(6.7)$} \\
\hline Slurred speech & \multicolumn{2}{|l|}{$1(3.0)$} \\
\hline Dual incontinence & \multicolumn{2}{|l|}{$1(3.0)$} \\
\hline Unsteady gait (ataxia) & \multicolumn{2}{|l|}{$1(3.0)$} \\
\hline \multicolumn{3}{|c|}{ Record of GCS before and after surgery ${ }^{\mathrm{b}}$} \\
\hline GCS & Before surgery & After surgery \\
\hline $13-15$ & 2 & 6 \\
\hline $9-12$ & 0 & 1 \\
\hline$<9$ & 5 & 1 \\
\hline
\end{tabular}

${ }^{a}$ Out of 13 patients who had a positive history of head injury, the cause could not be identified for 2 patients as relatives recalled a history of trauma but were unable to specify the circumstances. ${ }^{b} \mathrm{GCS}$ before and after surgery was recorded in only $8(26.6 \%)$ patients 
On examination, the most commonly identified features were hemiparesis (63.3\%), abnormal plantar reflexes (53.3\%), and abnormal deep tendon reflexes (43.3\%). Deep tendon reflexes were brisk unilaterally in 8 patients $(26.7 \%)$, brisk bilaterally in $1(3.3 \%)$, and depressed bilaterally in 4 (13.3\%). All 30 patients underwent CT imaging which demonstrated a unilateral $\mathrm{CSDH}$ in 21 (70.0\%), bilateral CSDH in 5 (16.7\%), unilateral acute-on-chronic SDH in 3 (10.0\%), and unilateral subacute SDH in 1 (3.0\%) (Table 2).

Once CT scan results were obtained, 22 (73.3\%) patients underwent surgery for drainage of the hematoma, 19 patients underwent a burr-hole procedure, and 3 patients underwent a craniotomy.

Reasons for not transferring the patient to the surgical ward for urgent drainage of the SDH varied; often, these were denial by the patient or caregivers to undergo the procedure despite counseling, refusal on the part of the family due to advanced age of the patient, and comorbidities or an unstable patient condition with a high risk of a poor surgical outcome.

Out of the 22 patients who underwent drainage of the $\mathrm{SDH}, 68.1 \%(n=15)$ had notable improvement of their symptoms and neurological examination. Increase in muscle grading and mental status was considered as improved status. The overall mortality rate before discharge in the study cohort was $20.0 \%(n=6)$; death occurred in 4 patients following surgery and in 2 patients who did not undergo any surgical intervention (see Table 3).

\section{Discussion}

The increasing global incidence of CSDH because of an aging population has a great disease burden [15, 16]. This study demonstrates the challenges patients and physicians face in a Tanzanian referral hospital regarding management of CSDH. A relatively simple neurosurgical treatment can improve functional outcome; however, there is still a high mortality in our setting which can be explained by lack of adequate medical infrastructure, low insurance levels of the population, and the delayed recognition on presentation which are not uncommon in a low-resource country [3].

Clinically, patients often present with a history of gradually increasing altered level of consciousness and focal signs, only to enter hospital at a very advanced

Table 2 Radiological findings on CT scans

\begin{tabular}{lll}
\hline CT scan finding & $n$ & $\%$ \\
\hline Unilateral CSDH & 21 & 70.0 \\
Bilateral CSDH & 5 & 16.7 \\
Unilateral acute-on-chronic SDH & 3 & 10.0 \\
Unilateral sub-acute SDH & 1 & 3.0 \\
\hline
\end{tabular}

Table 3 Progress of patients admitted with SDHs

\begin{tabular}{llll}
\hline & Surgery $(n, \%)$ & No surgery $(n, \%)$ & Total $(n, \%)$ \\
\hline Improved & $15(50.0)$ & $1(3.0)$ & $16(53.3)$ \\
Worsened & $2(6.7)$ & $0(0.0)$ & $2(6.6)$ \\
Deceased & $4(13.3)$ & $3(10.0)$ & $7(23.3)$ \\
No change & $1(3.0)$ & $4(13.3 \%)$ & $5(16.7)$ \\
Total & $22(73.3)$ & $8(26.6)$ & $30(100)$ \\
\hline
\end{tabular}

Symptom and neurological examination progression from admission through to discharge

stage [6]. Often, no history of trauma is reported, or such information is unavailable as there are no relatives to reliably clarify the history in case the patient is unable to give an account of events leading up to admission. The reason is the considerable delay in referral and diagnosis, caused by the lack of medical infrastructure in a fragile healthcare system and lack of finances in lowresource settings.

Inability, often due to lack of funds, to complete imaging at the point of admission in a patient presenting with acute or chronic neurological deficits and no clear history of trauma would inevitably result in admission to the Internal Medicine Ward. This often translates into a prolonged time to obtain a definitive diagnosis, with additional delays caused by efforts from the family to arrange for funding to complete imaging investigations-CT scans cost roughly 110 United States dollars. In patients whose imaging demonstrates a subdural hematoma, a transfer to the general surgery ward for urgent burr-hole or craniotomy and evacuation of the subdural hematoma is arranged with priority.

Jivanjee's dissertation discussed chronic subdural hematomas that were admitted to both the medical and surgical wards of a Kenyan tertiary hospital [17]. Out of 51 patients who presented over 3 years, 37 (72.5\%) were initially admitted to the medical ward due to a diverse array of neurological complains which did not lead to a definitive diagnosis [17]. The challenge of diagnosis without readily available imaging was also reflected in his report as in 5 (9.8\%) individuals, the diagnosis was made during autopsy and 9 (17.6\%) individuals have been incorrectly diagnosed with a psychiatric condition [17].

Although the choice of the most ideal surgical procedure, burrhole versus craniotomy, for SDH drainage has been debated by authors in medical literature, at our center, often only the instruments to perform burrholes are present [18]. An overwhelming majority of patients requiring drainage of a $(\mathrm{C}) \mathrm{SDH}$ or even an epidural hematoma would undergo a burrhole.

The higher mortality rate even in patients who underwent surgical treatment might also be explained by the fact that there is no neurosurgical expertise available at our institution and the procedures are conducted by 
general surgeons. Out of 22 patients in our cohort who underwent surgery, improvement in symptoms and on serial neurological examination was noted in 15 (68.1\%). The long standing raised intracranial pressure due to a chronic subdural bleed would inevitably lead to some degree of irreversible brain damage. There is an increasing need for neurosurgical training and capacity in subSaharan Africa [19, 20].

Incomplete record keeping practices presented a significant problem during the data collection process. The authors acknowledge that the low proportion of patients for whom a GCS was recorded signify a major drawback in terms of completing a standardized assessment of patient status before and after surgery. In a low-income country, this is often difficult to improve [3].

The rate of clinical follow-up for patients is very low in our setting, and long-term progress of patients could not be recorded. Once a diagnosis like CSDH has been established and patients are referred to surgery for drainage, logistics, financial, or sociocultural restrictions-the preference for traditional healers-make many patients prefer not to return for follow-up [21]. Delay in surgical drainage of a chronic subdural bleed would inevitably result in irreversible damage from long standing raised intracranial pressure.

The old age of the study cohort implies a longer convalescence period as well as a more pronounced need for access to rehabilitation services. In an area where healthcare provision is already strained by the growing burden of infectious and non-infectious diseases, the procurement of additional resources required to deliver rehabilitation services may not be given a priority [22-24].

A history of head injury was present in $43.3 \%$ of the patients and signifies risk factors at play which can be addressed. The enhancement of primary prevention measures to improve road safety and to make the environment safer for the elderly population would inevitably reduce the burden of this vulnerable population. However, some factors are intrinsically linked to the setting, such as a mountainous terrain and heavy rainfall.

Apart from the considerable loss to follow-up, we have not been able to establish the measures of prevalence and incidence of SDHs in the general population for several reasons. Patients in whom there is a clear history or suspicion of acute head injury will have been referred directly to the Surgical Department, as were confirmed SDHs referred from outside our center.

Regardless of the missing data, there is indisputably a considerable attribution of CSDH to the neurological patient population in our Medical Department. In almost half of our patients (43.3\%), there is a recorded history of head injury and almost all presented so advanced that the high mortality of $23.3 \%$ can be explained.

\section{Conclusion}

In conclusion, the recognition and management of CSDHs in North Tanzania involves navigating the challenges of accessibility to diagnostic imaging, improving clinical acuity, overcoming the cost of surgery, and the challenging path to recovery for a largely elderly cohort.

\section{Abbreviations}

CSDH: Chronic subdural hematoma; CT: Computed tomography; GCS: Glasgow Coma Scale; KCMC: Kilimanjaro Christian Medical Centre; SDH: Subdural hematoma

\section{Acknowledgements}

Not applicable.

\section{Authors' contributions}

SMR and SSD contributed towards data collection, data analysis, and manuscript preparation. MCJD and WPH contributed towards data collection, manuscript preparation, and supervision of the work. All authors read and approved the final manuscript.

\section{Funding}

Not applicable.

\section{Availability of data and materials}

The data that support the findings of this study are available from the Department of Medical Records of Kilimanjaro Christian Medical Centre, but restrictions apply to the availability of these data, which were used under license for the current study, and so are not publicly available. Data are however available from the authors upon reasonable request and with permission from the Administration of Kilimanjaro Christian Medical Centre.

\section{Ethics approval and consent to participate}

This study was approved of the by the Medical Ethics Committee of Kilimanjaro Christian Medical Centre, Moshi, United Republic of Tanzania.

\section{Consent for publication}

Not applicable.

\section{Competing interests}

The authors declare that they have no competing interests.

\section{Author details}

${ }^{1}$ Department of General Surgery, Kilimanjaro Christian Medical Centre, P.O. Box 3010, Moshi, Tanzania. '2Department of Neurology, Radboudumc, 6525 GA Nijmegen, The Netherlands. ${ }^{3}$ Department of Internal Medicine, Kilimanjaro Christian Medical Centre, P.O. Box 3010, Moshi, Tanzania. ${ }^{4}$ Department of Pediatrics and Child Health, Kilimanjaro Christian Medical Centre, P.O. Box 3010, Moshi, Tanzania. ${ }^{5}$ Department of Orthopedics and Trauma, Kilimanjaro Christian Medical Centre, P.O. Box 3010, Moshi, Tanzania.

Received: 19 May 2019 Accepted: 16 September 2019

Published online: 09 October 2019

\section{References}

1. Walker ME, Espir M, Shephard RH. Subdural haematoma: presentation and diagnosis on medical wards. Postgrad Med J 1968;44:785-91.

2. Yang Al, Balser DS, Mikheev A, Offen S, Huang JH, Babb J, Rusinek $H_{\text {, }}$ Samadani U. Cerebral atrophy is associated with development of chronic subdural haematoma. Brain Inj 2012;26:1731-6.

3. Dekker MCJ, Urasa SJ, Howlett WP. Neurological letter from Kilimanjaro. Pract Neurrol. 2017;5:412-6.

4. Kudo H, Kuwamura K, Izawa I, Sawa H, Tamaki N. Chronic subdural hematoma in elderly people: present status on Awaji Island and epidemiological prospect. Neurol Med Chir 1992;32:207-9.

5. Adhiyaman V, Chatoopadhyay I, Irshad F, Curran D, Abraham S. Increasing incidence of chronic subdural haematoma in the elderly. QJM. 2017;110:375-8.

6. Bankole OB, Yusuf AS, Kanu OO, Ukponwan E, Nnnadi MN, Arigbabu SO. Chronic subdural haematoma: clinical presentation, surgical treatment and outcome at the Lagos university teaching hospital. Afr J Neurol Sci 2011;30:10-7. 
7. Dakurah TK, Iddrissu M, Wepeba G, Nuamah I. Chronic subdural haematoma: review of 96 cases attending the Korle Bu Teaching Hospital. Accra West Afr J Med. 2005;24:283-6.

8. Djientcheu V, Esiene A, Yamgoue T, Tchaleu B, Minkande JZ. Surgical treatment and outcome of 195 cases of non acute subdural haematoma at the Youndé Central Hospital: The need for landmarked burr holes. Afr J Neurol Sci. 2011;30(2).

9. Maiga AH, Sakho Y, Ba MC, Ndoye N, Thiam AB, Diallo M, Badiane SB. Chronic subdural hematomas in Dakar: clinical, diagnostic, therapeutic and evolving features in the age of the scanner (apropos of 88 cases). Mali Med. 2008:23:11-6.

10. Mezue WC, Ohaebgulam SC, Chikani MC, Erechukwu AU. Changing trends in chronic subdural haematoma in Nigeria. Afri J Med Med Sci. 2011;40:373-6.

11. Mwanyombet-Omphounga L, Loembe FA, Loembe PM. Traitment des hematomes sour-duraux chroniques a libreville (Gabon): Revue de 102 cas. Afr J Neurol Sci. 2011;30(2).

12. Hode L, Quenum K, O Fatigba H, Fanou L, GS Lansdale H. Treatment and outcome of chronic subdural hematoma in sub-Saharan Africa and the country of Benin. Iran J Neurosurg 2015;15:31-35.

13. Fatigba HO, de Tove MK, Tchaou BA, Mensah E, Allode AS, Padonou J. Surgical management of head trauma: problems, results, and perspectives at the departmental teaching hospital of Borgou, Benin. World Neurosurg. 2013;80:246-50.

14. Kanyi JK, Ogada TV, Oloo MJ, Parker RK. Burr-hole craniostomy for chronic subdural hematomas by general surgeons in rural Kenya. World J Surg 2018; 42:40-5.

15. Karibe H, Kameyama M, Kawase M, Hirano T, Kawaguchi T, Tominaga T. Epidemiology of chronic subdural hematomas. No Shinkei Geka 2011;39: 1149-53.

16. Balser D, Farooq S, Mehmood T, Reyes M, Samadani U. Actual and projected incidence rates for chronic subdural hematomas in United States Veterans Administration and civilian populations. J Neurosurg 2015;123:1209-15.

17. Jivanjee SA. A study of chronic subdural hematomas at Kenyatta National Hospital Nairobi: University of Nairobi Research Archive; 1979. http://erepository. uonbi.ac.ke/handle/11295/25969?show=full. Accessed 14 June 2019

18. Regan JM, Worley E, Shelburne C, Pullarkat R, Watson JC. Burr hole washout versus craniotomy for chronic subdural hematoma: patient outcome and cost analysis. PLoS One 2015;10:e0115085.

19. El Khamlichi A. African neurosurgery: current situation, priorities, and needs. Neurosurgery. 2001;48:1344-7.

20. El-Fiki M. African neurosurgery, the 21st-century challenge. World Neurosurg. 2010;73:254-8.

21. Brinda EM, Andrés RA, Enemark U. Correlates of out-of-pocket and catastrophic health expenditures in Tanzania: results from a national household survery. BMC Int Health Hum Rights. 2014;14:5.

22. Nyaaba GN, Stronks K, de Graft AA, Kengne AP, Agyemang C. Tracing Africa's progress towards implementing the Non-Communicable diseases Global action plan 2013-2020: a synthesis of WHO country profile reports. BMC Public Health 2017;17:297.

23. Osakunor DN, Sengeh DM, Mutapi F. Coinfections and comorbidities in African health systems: at the interface of infectious and non-infectious diseases. PLoS Negl Trop Dis 2018;12:e007611.

24. Njelesani J, Couto S, Cameron D. Disability and rehabilitation in Tanzania: a review of the literature. Disabil Rehabil 2011;33:2196-207.

\section{Publisher's Note}

Springer Nature remains neutral with regard to jurisdictional claims in published maps and institutional affiliations.

\section{Submit your manuscript to a SpringerOpen ${ }^{\circ}$ journal and benefit from:}

- Convenient online submission

- Rigorous peer review

- Open access: articles freely available online

- High visibility within the field

- Retaining the copyright to your article

Submit your next manuscript at $\boldsymbol{\nabla}$ springeropen.com 